\title{
Turning experience into theory: The affirmation model as a tool for critical Praxis
}

\author{
Colin Cameron ${ }^{1}$
}

\begin{abstract}
In this article I discuss the affirmation model, initially proposed by Swain and French (2000), as an intervention in an ongoing debate within disability studies around the usefulness of the social model. I consider the purpose of developing models, such as the social and affirmation models, and identify the lack of definitions in Swain and French's original suggestion as an inherent weakness. I then outline my own research, undertaken with the aim of identifying whether useful affirmation model definitions might be fashioned, and relate my conclusions to Freire's idea of critical Praxis. I conclude by proposing the affirmation model as a practical tool for use by social workers to identify the ways in which disabling social relations are reproduced in everyday encounters..
\end{abstract}

Keywords: impairment; disability; medical model; social model; affirmation model; critical Praxis

1. Senior Lecturer BA Joint Hons Disability Studies

Address for correspondence: Department of Social Work and Communities, Faculty of Health and Life Sciences, Niorthumbria University, Coach Lane Campus, Newcastle upon Tyne NE7 7XA. colin.cameron@northumbria.ac.uk 


\section{Introduction}

In this article I discuss the affirmation model, initially proposed by Swain and French (2000), as an intervention in an ongoing debate within disability studies around the usefulness of the social model. I consider the purpose of developing models, such as the social and affirmation models, and identify the lack of definitions in Swain and French's original suggestion as an inherent weakness. I then outline my own research, undertaken with the aim of identifying whether useful affirmation model definitions might be fashioned, and relate my conclusions to Freire's idea of critical Praxis. I conclude by identifying the affirmation model as a practical tool for use in social work practice.

\section{Models of disability}

Debate about the usefulness of the social model has existed within Disability Studies almost since Oliver coined the term to describe the definitions set out in the UPIAS document Fundamental Principles of Disability (Union of the Physically Impaired Against Segregation, 1976; Oliver, 1990; Barnes, 2014). While the medical model establishes a view which identifies disability as physical incapacity or abnormality resulting from impairment (WHO, 1980), the strength of the social model lay in the fact that it offered a fundamental alternative to this individualising perspective (Oliver and Barnes, 2012). It identified disability as an oppressive social relationship and as a matter of how society responds - or fails to respond - to the needs of people with impairments. It made clear the perception that not only has society omitted to include people with impairments, but that through its provision of segregated environments and institutions such as residential homes, day centres and 'special' schools, it has consciously organised itself to exclude people with impairments from ordinary life. From a social model view disability ceases to be something that people 'have' and is understood instead as something 'done to' people with impairments. People have impairments but are not 'people with disabilities'. They are disabled by poor or non-existent access to the public places where ordinary life happens and by the condescending and unwelcoming responses of those who occupy these spaces. What this suggests is that action needs to be taken to identify and remove the barriers which have excluded people with impairments from participation as equals in everyday community life. As Oliver has stated, the social model is not about the personal experience of impairment but the collective experience of disablement (Oliver, 2004). It is a call to action.

Criticism of the social model came in particular from disabled feminists who argued that the social model over-emphasised socio-structural barriers and ignored personal and experiential aspects of disability; that it ignored or was unable to deal adequately with subjective experiences of the 'pains' of both impairment and 
disability (Oliver, 2004). Morris (1991), for example, suggested that the social model tends to deny the experiences of disabled people's bodies. Crow called for a renewed social model which would allow 'a more complete recognition and understanding of individual's experiences of their body' (1996, p.210). Thomas (1999), advocating a social relational model of disability, argued that impairment and impairment effects should not be regarded as 'natural' or as pre-social, 'biological' phenomena. She made the point that the way in which impairment and impairment effects are perceived by others and, as a consequence, experienced by disabled people, is shaped by the interaction of biological and social factors. The meaning attributed to impairment profoundly determines the sense that can be made of the experience of living with impairment. In this sense, at the level of everyday experience, she concluded, disability and impairment effects interact.

One intervention within this ongoing debate was made in 2000 by Swain and French who proposed an affirmation model (2000). Rooting their idea in perspectives emerging from the disability arts movement, through which disabled people were retelling their individual and collective stories on their own terms and in their own voices and developing a sense of disability pride (Cameron, 2009), the affirmation model was proposed as a critique of the personal tragedy assumptions underlying the medical model. In this way it corresponded to the social model as a critique of the medical model.

The affirmation model was, Swain and French stated:

essentially a non-tragic view of disability and impairment which encompasses positive social identities, both individual and collective, for disabled people grounded in the benefits of lifestyle of being impaired and disabled (Swain and French, 2000, p.569).

In proposing an affirmation model, Swain and French set out a position from which it could be asserted that, far from being necessarily tragic, living with impairment can be experienced as valuable, interesting and intrinsically satisfying. This is not to deny there can be negative experiences resulting from impairment, but to make the point that this is not all that impairment is about. While Swain and French made it very clear that the affirmation model builds upon the social model (rather than being proposed as an alternative) they suggested that the need for an affirmation model is established in that it is not a purpose of the social model to reject a tragic view of impairment:

even in an ideal world of full civil rights and participative citizenship for disabled people, an impairment could be seen to be a personal tragedy (Swain and French, 2000, p.571). 


\section{Models and definitions}

In describing the social model of disability as 'a hammer for justice and freedom' Oliver draws attention to its nature as 'a practical tool, not a theory, an idea or a concept' $(2004$, p.11, 12). He states that 'we have spent too much time talking about the social model and its usefulness and indeed its limitations and not enough time actually implementing or attempting to implement it in practice' (2004, p.7). His point is clear. The purpose of developing models is to make use of them. While a model may be an abstract construction, it is one that has been developed intentionally to enable us to think about ideas and concepts, about how these relate to the world, and about how to act upon our conclusions. Models are frameworks which not only structure the thoughts, ideas and concepts we hold in our heads and give order to what we know (or think we know) about the world, but also suggest ways of acting upon the world (Cameron, 2014a).

Models are never neutral, but always reflect the interests of those who have developed them. We need to understand that however natural and inevitable ways of relating to the world and its objects appear, there is little about how we come to understand either ourselves or anybody else around us that is not determined by the way we are situated within complex networks of institutional patterns and arrangements. These structure our perceptions of, e.g. gender, race, age, class, impairment and disability (Burr, 2003), each reflecting certain assumptions embedded within explanatory and predictive models. What we know is learned and what we learn is moulded by the places and times we find ourselves and by how these are explained to us.

Ideology works most effectively when it presents itself as just the way things are (Gramsci, 1996), and what Oliver (2009) has termed 'the ideology of normality' is given strength by the medical model of disability. Medical model thinking is considered uncontroversial because it underpins legislation, policy and service delivery and is embedded within everyday life practices ${ }^{1}$. At the same time it is experienced by disabled people as problematic in that it is materialised in everyday life through the myriad of behaviours, decisions, and interactions taking place in the contexts in which they experience their lives. It is put into practice in words spoken and thoughts unspoken, gestures and assumptions made, hopes and expectations held. Because it is a dominant model of disability, reflecting the view of the world of the non-disabled, its character as a model, as a way of looking at things, is almost always overlooked. Medical model thinking does not appear as just 'one way of looking' but as established fact. It is considered common sense to regard impairment as misfortune. This impacts upon disabled people's lives not just in terms of professional judgements about what are appropriate services, but in terms of the restriction of life opportunities, experiences and roles (Cameron, 2014a).

The social model itself is not complicated. It consists simply of two definitions. Impairment is categorised as 'lacking part of or all of a limb, or having a defective 
limb, organ or mechanism of the body'; while disability is defined as 'the disadvantage or restriction of activity caused by a contemporary social organisation which takes little or no account of people who have physical impairments and thus excludes them from the mainstream of social activities' (UPIAS, 1976, p.14). Yet these two definitions have made possible a critical gaze at both contemporary and historical social relations as these have shaped the experiences of countless disabled people. They have established the basis for a movement of disabled people, regardless of specific types of impairments, to collectively campaign for equality. They have provided the ontological and epistemological foundation for research practice which challenges traditional disability research relations.

While the affirmation model proposed by Swain and French offered a new way of reflecting on the lived experience of impairment, it was weakened by the fact that it lacked definition and structure. While Swain and French had described what the affirmation model was about and what it was like (Swain and French, 2000, p.580) they had stopped short of specifying what it was (Cameron, 2008). It lacked those definitions which would turn it into a tool that could be used practically. On a personal level, as a disabled person involved in both disability arts and disability studies, I felt this was unfortunate because I thought the affirmation model was a good idea. But I also thought that it was a good idea which, without further work, was in danger of remaining just that.

In 2006 I was awarded a PhD bursary by Queen Margaret University, Edinburgh, to develop research enquiring, among other things, whether useful affirmation model definitions of impairment and disability might be fashioned. To this purpose I completed a series of interviews, conversations and observations with 16 disabled people from Scotland and England, involving people with a range of physical, sensory, emotional and cognitive impairments; with congenital and acquired impairments; who lived in isolated rural settings as well as town and city environments; black, white, gay and straight disabled people; who had and who did not have religious faith; came from a variety of class backgrounds; and who were aged from their early 20 s to their mid-50s. Research participants were identified through purposive sampling, having responded to an e-bulletin outlining the project initially posted by the disabled people's organisation (d.p.o.) Inclusion Scotland and re-posted by other d.p.o.s and charities. Originally I asked for responses from people who felt strong and positive about being disabled, people who saw being disabled as just something to get on with but not to go on about, and people who described themselves as really hating the experience. Receiving a large number of responses, however, I was able to broaden my recruitment criteria in order to try and include as wide a range of social and personal characteristics as possible. The research involved, with each participant, semi-structured interviews around their life experiences and around ways in which they had learned about and come to relate to the idea of disability; unstructured interviews about their perceptions of media representations of disabled people as resources to draw on in making sense of the experience of impairment; 
and go-along observations as they engaged in a range of ordinary, everyday activities including, for example, crossing Birmingham New Street railway station, going shopping for a pair of slippers, going to a 60s disco, and watching an episode of the TV game show Deal Or No Deal (Cameron, 2010).

\section{Impairment as difference, disability as role}

I would like here to reflect on three particular moments in my research. Rose is an artist, a wheelchair-user living in the Scottish highlands, who was at the time of my study in her early 50s. Surinder is an Asian woman working for an organisation of disabled people in Glasgow, also a wheelchair user, who was in her early 40s. Charles is a self-employed wheelchair-user who lives in Liverpool, and who was at the time in his early 30 s.

\section{Rose}

Rose took me around the centre of the highland town where she lives to let me see some of the barriers she encounters as a wheelchair user whenever she comes shopping. She had some things she would have wanted to buy anyway and we agreed that as she went about her business of making purchases she would point out the barriers as she faced them. I should feel free, Rose told me, to note what I liked, including any interpersonal encounters. She showed me the restaurants she would like to go to but cannot get into; the inaccessible cash machine and the wheelchair lift into the bank that has to be operated by a member of staff whose attention she has to attract from outside; the hairdresser's she uses, not because it has a good reputation but because it has access to the basins; the theatre which has an automatic door that is never switched on and a stair-lift she has to ride on while strangers walking up the stairs ask her if she is enjoying herself; the unreachable high and low shelves in the supermarket; the inaccessible customer lift in the department store; and the difficult ramp at Costas coffee shop that has to be charged at, so that people sitting by the window stare in fright, thinking that she is going to come crashing through. We spoke with a number of shop assistants who were sympathetically apologetic that things weren't better and promised that improvements were being looked at.

We made a visit to W.H. Smith's, the stationer's. Rose had recently been given some W.H. Smith's vouchers as a birthday present and wanted to spend these on classical music. The music section in this shop was on the first floor. Rose found a sales assistant, a middle-aged woman probably slightly younger than herself.

'I'd like to buy some music,' said Rose. 'Can I use the lift?' 
'Sorry,' said the assistant. 'We've been measured for a new lift but it's not been fitted yet.'

'Can I use the service lift, then?'

'No,' she said.

'I've got W.H. Smith's vouchers. Can I change them for cash, then?'

'No,' said the assistant. 'But I could go up and get a selection down.'

'Do you have any Mozart?'

'We mostly do chart CDs,' the assistant said.

We waited five minutes. The assistant returned.

'Mozart's sold out,' she said. 'This is all the classical we've got.'

She proffered a sad handful.

This encounter was one of inequality. While the sales assistant's initial apology may have indicated an awkwardness or embarrassment about the lack of a customer lift, she was not prepared to consider Rose's suggestions of reasonable adjustments using the service lift to get to the first floor or exchanging her WH Smith vouchers for money. Her suggestion that she herself should go upstairs and bring down a selection not only limited Rose's opportunity for browsing and enjoying, taking the time to choose, part of the ordinary shopping experience, but made a secret of what else lay upstairs. Whether or not Mozart was in stock was not the issue. In the music section on the first floor, had she been able to get there, Rose's eye might have been caught by something else she wanted to listen to, something jazzy or bluesy. There was a politics involved in Rose's having to wait downstairs. Dependence was created in that she was expected to make a choice from among those limited C.D.s the sales assistant brought back down with her. Some disabled people in this situation might have felt a sense of obligation to buy. After all, the sales assistant had shown kindness in taking the trouble to go upstairs to fetch the classical C.D.s. As it happened, Rose was assertive enough to decline those she was offered.

The fact that, at the end of 2008, there was still no customer lift in W.H. Smith's in this highland town conveyed several messages to Rose. It was not expected that people like her would want to come into this shop, certainly not to go upstairs, to browse, to choose. They would not be valued as customers. Here was a sense of disconnection, of difference as inferiority, from the majority of other shoppers. While presumably well-intentioned, the shop assistant's response to this situation was one which invalidated Rose's subject position while affirming her own. She could walk upstairs, Rose could not.

Rose knew that she was experiencing inequality in this situation and it made her feel uncomfortable. In having decided that she would like to examine any Mozart C.D.s for sale she identified herself as a woman of discrimination and taste. Yet the power relationship involved in the encounter with the sales assistant was sensed as demeaning and belittling. Whereas Rose viewed herself as an educated woman who enjoys classical music, she was cast here as someone who cannot climb the stairs, and as a victim of misfortune. 


\section{Surinder}

Surinder discussed her portrayal in a number of newspaper photographs taken while she was involved in a 2006 media campaign for the MS Society. Considering a photograph which had been printed in The Glasgow Herald, she exclaimed:

Oh my goodness, he made me sit on the floor and ... and the way I'm sort ... the way I've got my hands on the black stick which is slanting ... erm ... and then my head is slanting ... er ... it just all portrays the full image of feel sorry for this person... feel sympathy for this person because it's...

The construction of Surinder's photographic image appears to have involved careful planning to ensure pathos. Surinder recalled her feelings of discomfort at the time the photo was taken:

I think the photo itself ... I mean, I remember it being taken at the time and thinking, I don't want you to do this... and I should have actually said that, I should have said no, I don't want to lean to one side, cos that leaning to one side... portrays an image of someone who's looking for...you know, I'm looking for pity ...

The text accompanying the photo gave a similarly bleak impression of Surinder's life:

For Surinder, even the simple tasks of filling her glass with water or chopping onions require enormous concentration and effort... negotiating a doorway often results in a bruise for the 38-year-old from Glasgow while a trip to the shops or a short walk along the beach can cause such fatigue that she becomes bedridden for several days...

While she accepted the basic facts described here, Surinder was annoyed by the way in which they were written. The impression was conveyed, she felt, that her life experience was of relentless misery. She drew attention to the story's headline:

I'm leading fight to help MS sufferers ...

The word sufferers I would never use in my life ... connotations of suffering and negativity and in the ground... I don't see myself as a sufferer, so why on earth ... I didn't have any say in that again ... if I'd known what the headline was going to be ... I would have said excuse me, no ... take that word out ... it's inappropriate and it's not accurate ...

While Surinder is a confident, assertive, and vivacious Asian woman, The Herald's narrative depicted her as a sufferer whose life is blighted by tragedy. The triumph 
over tragedy stereotype (Cameron, 2014c) was in evidence here, in that in spite her of affliction, she still has the courage to lead the fight to help others as unfortunate as her. She was not just to be pitied, but admired as well. The identity of sufferer was one that Surinder emphatically rejected. The aim of this photograph and story was to produce an emotional response in The Herald's readers. In the careful manufacture of this image, in requiring that Surinder sat on the ground, the prominent placing of her walking stick, the poised angling of her head, we can regard in detail the imposition of a tragic role. In and through these instructions Surinder was turned from being an Asian woman who has multiple sclerosis into a disabled person. Those who bought and read this edition of The Herald would presumably have been able to feel good about themselves because they had been reminded of their own good fortune in being able-bodied: unless, that is, they happened to be disabled themselves, in which case they would have been reminded of how bleak their own lives were.

\section{Charles}

When I was talking in the pub with Erin and yourself tonight... with every sentence I wasn't thinking oh, I'm going to say this sentence with a speech impairment... blah blah blah... now I'm going to say this with a speech impairment... blah blah blah... I'm going to move back, but I'm moving back in my wheelchair ... you know... you don't think... but ... when you catch somebody looking at you .... and looking at the effects of your impairment ... concentrating on your impairment ... then you're suddenly aware ... that you're speaking differently ...

Charles' statement here was made in reflecting afterwards upon the experience of having gone out earlier to a local pub with a friend for a meal. At one point in the evening, while Charles had been talking to Erin and I, a waiter had come up behind where he was sitting in his wheelchair to enquire if we wanted any more drinks. While Charles' consciousness had been focussed on our presence he had been holding forth with eloquence and humour, pausing occasionally to sip his veneto merlot cabernet 2007 through a straw. In our company Charles had been his usual laid back entertaining self. When he became aware of the gaze of the waiter standing behind him, however, his mode of awareness changed. He became an object for the other, and aware of himself as an object of scrutiny, fascination and perplexity. In other words he became aware of himself as a disabled person. The waiter - a young man - had hovered behind Charles for longer than is usually considered acceptable in terms of restaurant etiquette. Presumably waiting for what he considered an appropriate break in the conversation to make his intervention, relying upon cues and tones in what was being said, he had been thrown by Charles' speech impairment. The waiter had cast a number of appealing glances in my direction before Charles picked up on my body language noticing these appeals, and made his own shift in 
awareness modes. Charles' point in his statement above is that while impairment is not necessarily experienced as a problem for the person concerned as he is caught up in life's flow, he finds that it is often made a problem by other people around. It is not the experience of impairment which is negative, but other people's response to impairment.

Analysis of the data I gathered through my research interviews and observations led me to conclude that disability is an oppressive role imposed on people with impairments in their everyday encounters with the non-disabled. It is about what, in the midst and flow of everyday life, they are required to be and become for other people. I draw here on Young's description of structural oppression as involving 'the vast and deep injustices that some groups suffer as a consequence of often unconscious assumptions and reactions of well-meaning people in ordinary interactions' (Young, 1990, p.41). Assumptions identifying impairment as personal tragedy and regrettable difference are reflected in gestures, looks and words of sympathy and condescension that jar upon disabled people's experience. Implicit in these interactions is a requirement either to assent to the view of self being presented - as object of sympathy and condescension - or to protest by emphasizing one's own normality. Neither of these allows for an affirmation of impairment as an ordinary part of life. Young adds that:

The conscious actions of many individuals daily contribute to maintaining and reproducing oppression, but these people are usually simply doing their jobs or living their lives and do not understand themselves as agents of oppression (Young, 1990, p.42).

It is not that non-disabled people are conscious of their roles in the structural oppression of disabled people. Rather, the reverse might be said to be usually true: that they generally feel sympathy towards people with impairments and seek their welfare. But it is precisely in this relationship, in which sympathy is regarded as an appropriate response to impairment, that oppression takes place (Cameron, 2014d). As Young notes, 'for every oppressed group there is a group that is privileged in relation to that group' (1990, p.42). Disability is a role imposed within advanced societies which require a high degree of individual restraint and conformity (Elias, 2001). 'Fitting in' involves keeping up appearances, maintaining a narrative which says that 'all is well with us', constant attention to appearance and self-presentation. Within contemporary capitalism the constant generation of needs, consumption and profit requires individuals to identify themselves as consumers, continually purchasing goods to sustain their 'strategic image-presentation' (Lodziak, 2002, p.58). It is participation within contemporary life which produces this alienation. The non-disabled are required to respond to impairment as discreditable difference in order that they see advantage in their own conforming normality. Disabled people pose a challenge to the idea of 'the reasonable person' as standard because 
their embodiment serves as an unwelcome reminder of the frailty, temporality and contingency of human life (Cameron, 2014e). Toe affirm impairment, and positive identity as someone who lives with impairment, involves a determined transgression of dominant cultural values where culture is understood in terms of shared values and beliefs which legitimate particular social and institutional practices and forms of behaviour (Lister, 2010).

The affirmation model definitions I proposed were as follow:

Impairment: physical, sensory, emotional and cognitive difference, divergent from culturally valued norms of embodiment, to be expected and respected on its own terms in a diverse society.

Disability: a personal and social role which simultaneously invalidates the subject position of people with impairments and validates the subject position of those considered normal. (Cameron, 2010)

In identifying impairment as difference, the affirmation model requires recognition of impairment as an ordinary rather than an extraordinary characteristic of human experience, and for inclusion within ordinary life on that basis. It establishes the rights of people with impairments to feel okay about themselves and to take pride in who they are as people with impairments. In identifying disability as role, the affirmation model identifies disability as a productive as well as a restrictive relationship. This involves recognition not just of the parts of life people with impairments are excluded from, but of the kind of social actors they are required to become. Whether this involves roles of passive acceptance of the idea of being a victim of personal tragedy or steadfast denial of the significance of impairment, either way negates the lived experience of impairment and signifies the desirability of normality.

\section{Critical Praxis and the affirmation model}

In developing Marx's idea of Praxis - the unity of thought and action or active experience (Allman, 2001, p.40) - Freire (1976, p.33) defined the term as involving 'reflection and action upon the world in order to transform it'. Through Praxis, Freire argued, oppressed people can develop critical awareness of their own condition, and, with their allies, struggle for liberation. I suggest that the clarified affirmation model - expressed in the two definitions above - can be used as a practical tool in the purpose of developing such a critical Praxis. Finding themselves thrown into the world at a certain point and time, people participate within existing social relations and conditions which are, by and large, experienced and accepted as natural. The 
world and the way it is and the ways people relate to each other are presented pretty much as if these are the ways things always have been and always will be. The historical contingency of the present is easily obscured.

Using the social model, an understanding has been developed within disability studies of the relative recency of the emergence of disability as an organising social construct (Oliver and Barnes, 2012; Cameron, 2014f). Prior to the industrialisation of society in the $19^{\text {th }}$ Century people with impairments had been included within community life, or at least not systematically excluded. It is with the advent of the factory system, the introduction of new production norms, and the emergence of requirements for 'normal' standards of behaviour, embodiment and comportment (Davis, 2013) that people with impairments found themselves marginalised, institutionalised, and segregated from the social mainstream. It was as a part of this process that they became the focus of a medicalising gaze and of a burgeoning disability industry. As a social construct and as a role, disability is the ontological price paid by people with impairments for the relative security of identity of those who are able to conform with what society requires. In other words, disability itself is an oppressive social requirement.

In the way that all social structures are reproduced, re-enacted and reinforced in the details of everyday life, it is in daily encounters between people with impairments and non-disabled people that disabling social relations are reproduced. While the social model offers us a tool by which we are able to make sense of the big picture, it is my hope that the affirmation model might be used as a tool for making sense of those microagressions and invalidations which occur at the level of interpersonal social interaction. As Stryker (2002, p.66) observes:

If the social structure is shaped by interaction, it is social structure that shapes the possibilities for interaction and so, ultimately, the person. Conversely, if the social person creatively alters patterns of interaction, those altered patterns can ultimately change social structure.

In refusing to take on the roles we are expected to take on and to be the people we are expected to be - in refusing to hide or feel awkward about or ashamed of our impairments - disabled people are transgressing the social relations by which we are oppressed, and working towards the liberation Freire spoke of.

\section{Conclusion}

Freire spoke of the need for oppressed people to work with their allies, and there is a clear potential for social workers to take on this role. Jones and Novak (2014, p.11), addressing social workers, state: 
The legitimation of inequalities and the management of the poor has been a major pre-occupation of the British state. It is a critical arena of class struggle and one in which we must be engaged in the same deliberate and focused way as those who seek to sustain their power.

Disability is part of the division and segmentation of poverty and inequality into manageable sections to prevent it from erupting and pulling down the edifice of capitalism. This management has for long depended on 'keeping the gaze of the majority downwards so that people compare themselves with those beneath them rather than those above' (Jones and Novak, 2014, p.2). Drawing on and rooted in disabled people's accounts of their own experiences, the clarified affirmation model is intended for use in figuring out when, how and why this happens and in developing responses to challenge it when it does. It is for social workers to use in checking not only their own assumptions and the assumptions underlying their service cultures, but also for supporting disabled people with whom they work in developing critical awareness.

\section{Endnote}

1. A person is regarded as disabled under the UK Equality Act 2010 if they 'have a physical or mental impairment that has a 'substantial' and 'long-term' negative effect on their ability to carry out normal daily activities'. This reflects an understanding of disability as an individual problem rather than as a structural issue.

\section{References}

Allman, P. (2001) Revolutionary Social Transformation: Democratic Hopes, Political Possibilities and Critical Education. Westport, CT: Bergin and Garvey

Barnes, C. (2014) 'Reflections on doing emancipatory research'. in J. Swain, S. French, C. Barnes, and C. Thomas (Eds.) Disabling Barriers: Enabling Environments. (3rd ed.) London: Sage

Burr, V. (2003) Social Constructionism (2nd Ed.) London: Routledge.

Cameron, C. (2008) Further towards an affirmation model. in T. Campbell, F. Fontes, L. Hemingway, A. Soorenian, and C. Till (Eds.) Disability Studies: Emerging insights and perspectives.Leeds: The Disability Press

Cameron, C. (2009) 'Tragic but brave or just crips with chips? Songs and their lyrics in the Disability Arts Movement in Britain'. Popular Music, 28, 3, 381-396

Cameron, C. (2010) Does Anybody Like Being Disabled? A critical exploration of impairment, identity, media and everyday life in a disabling society. PhD thesis. Queen Margaret University. 
http://etheses.qmu.ac.uk/258/1/258.pdf

Cameron, C. (2014a) The Medical Model. in C. Cameron (Ed.) Disability Studies: A student's guide. London: Sage

Cameron, C. (2014b) Disability research. in C. Cameron (Ed.) Disability Studies: A student's guide. London: Sage

Cameron, C. (2014c) Stereotypes. in C. Cameron (Ed.) Disability Studies: A student's guide. London: Sage

Cameron, C. (2014d) Oppression. in C. Cameron (Ed.) Disability Studies: A student's guide. London: Sage

Cameron, C. (2014e) Alienation. in C. Cameron (Ed.) Disability Studies: A student's guide. London: Sage

Cameron, C. (2014f) The historical construction of disability. in C. Cameron (Ed.) Disability Studies: A student's guide. London: Sage

Crow, L. (1992) Renewing the social model. Coalition, July 1992, pp.5-9. Manchester: Greater Manchester Coalition of Disabled People

Davis, L.J. (2013) Disability, Normality and Power. in L.J. Davis,. The Disability Studies Reader. (4th ed.) London: Routledge

Elias, N. (2001) The Society of Individuals. London: Continuum

Freire, P. (1976) Pedagogy of the Oppressed. Harmondsworth: Penguin

Gramsci, A. (1996) Selections from the Prison Notebooks. London: Lawrence and Wishart

Jones, C. and Novak, T. (2014) 'We don't want to be ashamed tomorrow': Poverty, inequality and the challenge to social workers. in C. Jones and T. Novak (Eds.) Poverty and Inequality. Bristol: Policy Press

Lister, R. (2010) Understanding Theories and Concepts in Social Policy. Bristol: Policy Press

Lodziak, C. (2002) The Myth of Consumerism. London: Pluto Press

Morris, J. (1993) Pride Against Prejudice. London: The Women's Press

Oliver, M. (1990) The Politics of Disablement. Basingstoke: Macmillan

Oliver, M. (2004) 'If I had a hammer': The social model in action. in J. Swain, S. French, C. Barnes, and C. Thomas (Eds.) Disabling Barriers: Enabling environments. (2 ${ }^{\text {nd }}$ ed.) London: Sage

Oliver, M. and Barnes, C. (2012) The New Politics of Disablement. Basingstoke: Palgrave Macmillan

Swain, J. and French, S. (2000) 'Towards an Affirmation Model'. Disability and Society 15, 4, 569-582.

Thomas, C. (1999) Female Forms: Experiencing and understanding disability. Buckingham: Open University Press

Union of the Physically Impaired Against Segregation (1976) Fundamental Principles of Disability. London: UPIAS

WHO (1980) International Classification of Impairments, Disabilities and Handicaps. Geneva: World Health Organisation

Young, I. M. (1990) Justice and the Politics of Difference. Princeton, NJ: Princeton University Press 